Neurochemical Research, Vol. 10, No. 8, 1985, pp. 1019-1024

\title{
INHIBITION OF POLYPHOSPHOINOSITIDE PHOSPHODIESTERASE BY AMINOGLYCOSIDE ANTIBIOTICS*
}

\author{
Lucio A. A. Van Rooijen ${ }^{1}$ and Bernard W. Agranoff ${ }^{2}$ \\ Neuroscience Laboratory \\ Mental Health Research Institute \\ and \\ Department of Biological Chemistry \\ The University of Michigan \\ 1103 E. Huron \\ Ann Arbor, MI 48109
}

Accepted September 5, 1984

The calcium-activated phosphodiesteratic hydrolysis of ${ }^{32} \mathrm{P}$-labeled phosphatidylinositol 4,5-bisphosphate and phosphatidylinositol 4-phosphate in prelabeled nerve ending membranes is inhibited by the aminoglycosides neomycin and gentamicin, and to a lesser extent, by streptomycin. The inhibition is overcome by increasing concentrations of $\mathrm{Ca}^{2+}$, indicating that the aminoglycosides exert their effect by displacing $\mathrm{Ca}^{2+}$ from lipid.

\section{INTRODUCTION}

It has been known for some time that the aminoglycoside antibiotics bind tightly to polyphosphoinositides (1-3), and it has been proposed that their nephrotoxicity and ototoxicity may be related to their effects on the metabolism of these acidic lipids (4). It has previously been shown that these agents block phosphatidylinositol phosphate (PIP) kinase (5-7) and phosphatidylinositol 4,5-bisphosphate $\left(\mathrm{PIP}_{2}\right)$ and PIP monoesterase $(5,6,8)$.

* Dedicated to Professor Yasuzo Tsukada.

${ }^{1}$ Present Address: Neurobiology Department, Troponwerke, Berliner Str. 156, 5000 Cologne 80, Federal Republic of Germany.

2 To whom correspondence should be addressed. 
Downes and Michell (9) demonstrated endogenous phosphodiesteratic activity in erythrocytes ghosts that cleaves PIP $_{2}$ and PIP in the presence of $\mathrm{Ca}^{2+}$, and that the degradation could be blocked by aminoglycosides. Membranes derived from nerve endings, which in contrast to erythrocytes, support ligand-activated stimulation of lipid labeling also have phosphodiesteratic activity against the polyphosphoinositides (10). Since there has been much recent interest in the receptor-mediated phosphodiesteratic cleavage of the polyphosphoinositides, particularly of $\mathrm{PIP}_{2}$, to form diacylglycerol and inositol 1,4,5-trisphosphate $\left(\mathrm{IP}_{3}\right)$, we have examined the effects of aminoglycoside antibiotics on the activation by $\mathrm{Ca}^{2+}$ of the degradation of the polyphosphoinositides in prelabeled nerve ending membranes.

\section{EXPERIMENTAL PROCEDURE}

Membranes were prepared by sequential freezing, thawing and subsequent washing of nerve endings that had been prelabeled with ${ }^{32} \mathrm{P}_{\mathrm{i}}(10)$. Following further preincubation for $15 \mathrm{~min}$ in bulk, aliquots of the labeled membranes $(0.1-0.2 \mathrm{mg}$ of protein) were incubated under various conditions for $5 \mathrm{~min}$ at $37^{\circ} \mathrm{C}$ with shaking, in a final volume of $0.25 \mathrm{ml}$ of a buffer containing $30 \mathrm{mM} H E P E S / \mathrm{NaOH}(\mathrm{pH} 7.4)$ and $0.25 \mathrm{mM}$ EGTA. The incubations were terminated by the addition of $1.5 \mathrm{ml}$ of chloroform-methanol ( $1: 2 \mathrm{by}$ vol). Following extraction, lipids were separated by TLC, located autoradiographically, scraped and counted by liquid scintillation technique (10). Water-soluble compounds were separated on high voltage paper electrophoresis ( $\mathrm{pH}$ 1.5). Bands, located by autoradiography, were cut out and counted $(10,11)$. Protein was determined spectrophotometrically (12).

\section{RESULTS AND DISCUSSION}

Addition of $1 \mathrm{mM}$ neomycin or gentamicin to incubations of ${ }^{32} \mathrm{P}$-prelabeled nerve ending membranes resulted in inhibition of the $\mathrm{Ca}^{2+}$-activated diesteratic degradation of both PIP $_{2}$ and PIP (Table I). Streptomycin appeared much less potent in inhibiting the breakdown. The relative degree of inhibition corresponds with the known ability of the various aminoglycosides to displace $\mathrm{Ca}^{2+}$ from synaptic membranes (13). Neomycin caused a $50 \%$ inhibition of $\mathrm{PIP}_{2}$ and PIP breakdown at about $0.15 \mathrm{mM}$ and $0.35 \mathrm{mM}$, respectively. This is consistent with the higher affinity of neomycin for $\mathrm{PIP}_{2}$ than for PIP (1). Gentamicin also inhibited $\mathrm{PIP}_{2}$ breakdown more effectively than that of PIP. In experiments on erythrocyte membranes in which only the release of $\mathrm{IP}_{3}$ and inositol 1,4-bisphosphate $\left(\mathrm{IP}_{2}\right)$ were measured, Downes and Michell (9) obtained 50\% inhibition at 1 and $7 \mathrm{mM}$ neomycin, respectively. It should be noted in addition that 
AMINOGLYCOSIDES AND POLYPHOSPHOINOSITIDE DIESTERASE 1021

TABLE I

The Effect of Aminoglycosides on the Diesteratic Degradation of POLYPHOSPHOINOSITIDES

\begin{tabular}{lcc}
\hline & \multicolumn{2}{c}{ Inhibition (\%) } \\
\cline { 2 - 3 } Aminoglycoside & $\mathrm{PIP}_{2}$ & PIP \\
\hline Neomycin & $80.5 \pm 6.7$ & $57.8 \pm 2.7$ \\
Gentamicin & $74.1 \pm 3.2$ & $46.5 \pm 3.4$ \\
Streptomycin & $28.1 \pm 1.6$ & $24.9 \pm 0.7$ \\
\hline
\end{tabular}

Nerve ending membranes were incubated as described in the text, in the presence or absence of $0.4 \mathrm{mM}$ free $\mathrm{Ca}^{2+}$ and $1 \mathrm{mM}$ aminoglycoside as indicated. Since no significant effect of the aminoglycosides on radiotracer recovered as polyphosphoinositides was observed in the absence of $\mathrm{Ca}^{2+}$, these values were pooled. The values are expressed as percent inhibition of the $\mathrm{Ca}^{2+}$-induced loss of radiotracer, which was from $8716 \pm 137 \mathrm{cpm}$ (SEM, $n=12$ ) in the absence of $\mathrm{Ca}^{2+}$ to $4648 \pm 116 \mathrm{cpm}(\mathrm{SEM}, n=3)$ in the presence of $\mathrm{Ca}^{2+}$ for PIP and from $10076 \pm 157 \mathrm{cpm}(\mathrm{SEM}, n=12)$ to $5753 \pm 177 \mathrm{cpm}(\mathrm{SEM}, n=3$ ) for PIP.

these authors employed a higher membrane concentration $(2-2.5 \mathrm{mg} / \mathrm{ml}$ of protein) than used in the present study.

$\mathrm{Ca}^{2+}$ was required for the phosphodiesteratic degradation of the polyphosphoinositides, with an optimum in the region of $0.4-1.0 \times 10^{-3} \mathrm{M}$ (Figure 1). Higher concentrations of $\mathrm{Ca}^{2+}$ did not enhance further degradation of PIP and slightly inhibited PIP $_{2}$ breakdown. While concomitant release of the inositol phosphates could be observed, there also appeared to be breakdown of $\mathrm{IP}_{3}$ to $\mathrm{IP}_{2}$. This breakdown is known to be catalyzed by $\mathrm{Mg}^{2+}$ (14), and while it was not added, tightly bound $\mathrm{Mg}^{2+}$ may have nevertheless been present in the preparation. However, it should be noted that $\mathrm{Mg}^{2+}$-catalyzed monoesteratic degradation of $\mathrm{PIP}_{2}$ and PIP is not found under these conditions (10). ATP, and its non-hydrolyzable analog, APPCP, at $1 \mathrm{mM}$ concentrations, appeared to block $\mathrm{IP}_{3}$ breakdown, possibly by chelation of the residual $\mathrm{Mg}^{2+}$. The nucleotides were not employed in the present study, since they precipitated neomycin. Neomycin itself appeared to inhibit degradation of $\mathrm{IP}_{3}$ at higher $\mathrm{Ca}^{2+}$ levels. It can also be seen from Figure 1 that inhibition of the phosphodiesteratic activity by neomycin was most apparent at low $\left[\mathrm{Ca}^{2+}\right]$ and that the effect of the aminoglycoside on lipid degradation could be abolished by increasing the concentration of the cation.

Studies of PIP kinase (5-7) and polyphosphoinositide monoesterases $(5,6,8)$ as well as of phosphodiesteratic cleavage support the thesis that the aminoglycosides exert their effects by binding to the substrate rather than to the various enzymes. Although phosphatidylinositol binds ami- 


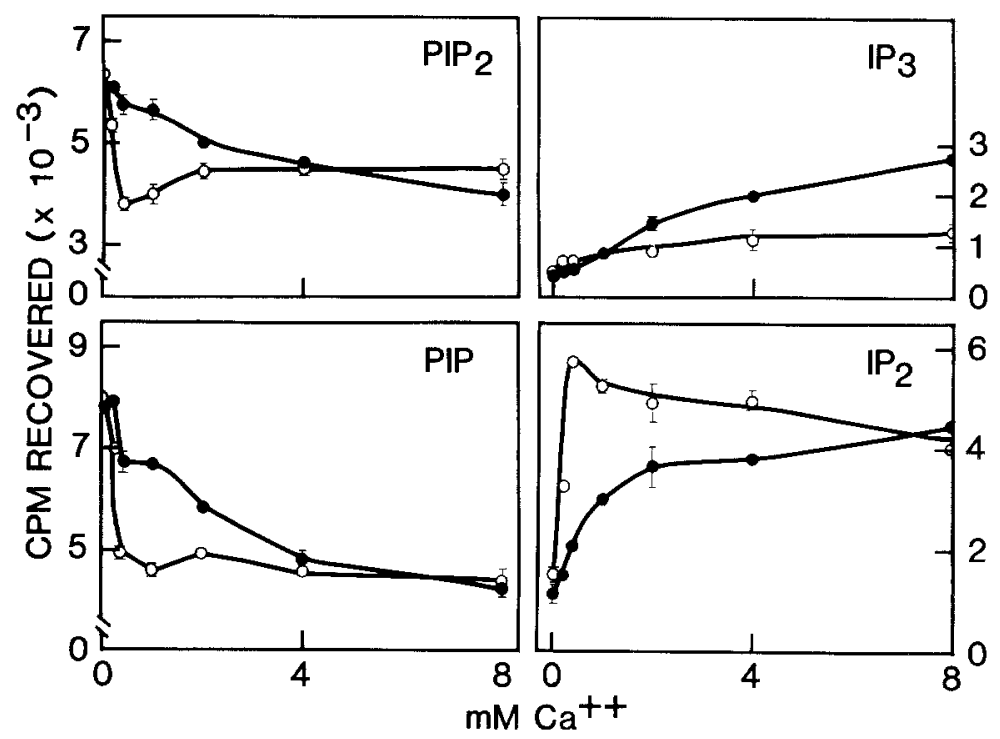

FIG. 1. The effect of neomycin on the phosphodiesteratic degradation of the polyphosphoinositides $\mathrm{PIP}_{2}$ and PIP to $\mathrm{IP}_{3}$ and $\mathrm{IP}_{2}$, respectively, activated by various concentrations of $\mathrm{Ca}^{2+}$. Nerve ending membranes were incubated as described in the text, in the presence $(\bullet)$ or absence $(O)$ of $1 \mathrm{mM}$ neomycin and various calculated concentrations (in EGTA buffer) of free $\mathrm{Ca}^{2+}$, as indicated. The incubations were terminated and the lipids and watersoluble compounds analyzed as described in the text. Each value represents the mean of duplicate determinations, from an experiment representative of 2-5 experiments.

noglycosides less tightly, similar observations have been made on the effects of aminoglycosides on the phosphodiesteratic breakdown of this lipid $(15,16)$. The present results are compatible with both the known binding of divalent cations to the polyphosphoinositides (17) and the requirement of $\mathrm{Ca}^{2+}$ for phosphodiesteratic cleavage. The aminoglycoside/ $\mathrm{Ca}^{2+}$ ratio may then affect availability of the substrate for the phosphodiesterase, and might account for the lack of an effect by neomycin on $\mathrm{Ca}^{2+}$-activated erythrocyte polyphosphoinositide phosphodiesterase by Marche et al. (7), in which a neomycin/ $\mathrm{Ca}^{2+}$ ratio of 0.3 was used in contrast to the results of Downes and Michell (9) who employed ratios of 2 and higher.

In the tissues in which ligand-stimulated degradation of polyphosphoinositides has been documented, there is preferential degradation of $\mathrm{PIP}_{2}$ (18). Attempts with membrane preparations to demonstrate a differential susceptibility of the two polyphosphoinositides to $\mathrm{Ca}^{2+}$-activated phosphodiesteratic degradation do not yet permit discrimination of $\mathrm{PIP}_{2}$ from 
PIP breakdown (10). The availability of bound inositides to $\mathrm{Ca}^{2+}$ and aminoglycosides appear to be rather similar. While the present results suggest that $\mathrm{PIP}_{2}$ in nerve ending membranes may bind $\mathrm{Ca}^{2+}$ somewhat better than PIP, the consequent effect on the diesteratic degradation does not appear to be sufficient to account for the observed difference in selectivity seen in ligand-stimulated degradation of PIP $_{2}$ in intact cells and $\mathrm{Ca}^{2+}$-activated cleavage in membrane preparations.

\section{ACKNOWLEDGMENTS}

The authors thank Dr. Jochen Schacht for helpful discussions. This work was supported by NIH grant NS 15413 .

\section{REFERENCES}

1. Schacht, J. 1978. Purification of polyphosphoinositides by chromatography on immobilized neomycin. J. Lipid Res. 19:1063-1067.

2. Palmer, F. B. St. C. 1981. Chromatography of acid phospholipids on immobilized neomycin. J. Lipid Res. 22:1296-1300.

3. Sastrasinh, M., Knaus, T. C., Wernberg, J. M., and Humes, H. D. 1982. Identification of aminoglycoside binding site in rat renal brush border membranes. J. Pharmacol. Exp. Therap. 222:350-358.

4. Humes, H. D., Weiner, N. D., and SCHACHT, J. 1982. The biochemical pathology of aminoglycoside-induced nephro- and ototoxicity. Pages 333-343, in Fillastre, J. P. (ed.), Nephrotoxicity and Ototoxicity of Drugs, INSERM, Paris.

5. SCHACHT, J. 1976. Inhibition by neomycin of polyphosphoinositide turnover in subcellular fractions of guinea-pig cerebral cortex in vivo. J. Neurochem. 27:1119-1124.

6. SCHIBECI, A., and ScHACHT, J. 1977. Action of neomycin on the metabolism of polyphosphoinositides in the guinea pig kidney. Biochem. Pharmacol. 26:1769-1774.

7. Marche, P., Koutouzov, S., and Girard, A. 1983. Impairment of membrane phosphoinositide metabolism by aminoglycoside antibiotics: streptomycin, amikacin, kanamycin, dibekacin, gentamicin and neomycin. J. Pharmacol. Exp. Therap. 227:415-420.

8. Roach, P. D., and Palmer, F. B. ST. C. 1981. Human erythrocyte cytosol phosphatidylinositol-bisphosphate phosphatase. Biochim. Biophys. Acta 661:323-333.

9. Downes, C. P., and MiChell, R. H. 1981. The polyphosphoinositide phosphodiesterase of erythrocyte membranes. Biochem. J. 198:133-140.

10. Van Rooijen, L. A. A., Seguin, E. B., and Agranoff, B. W. 1983. Phosphodiesteratic breakdown of endogenous polyphosphoinositides in nerve ending membranes. Biochem. Biophys. Res. Commun. 112:919-926.

11. Seiffert, U. B., and Agranoff, B. W. 1965. Isolation and separation of inositol phosphates from hydrolysates of rat tissues. Biochim. Biophys. Acta 98:574-581.

12. BRADFORD, M. 1976. A rapid and sensitive method for the quantitation of microgram quantities of protein utilizing the principle of protein-dye binding. Anal. Biochem. $72: 248-254$. 
13. LODHI, S., WEINER, N. D., and SCHACHT, J. 1976. Interactions of neomycin and calcium in synaptosomal membranes and polyphosphoinositide monolayers. Biochim. Biophys. Acta 426:781-785.

14. Downes, C. P., Mussat, M. C., and Michell, R. H. 1982. The inositol trisphosphate phosphomonoesterase of the human erythrocyte membrane. Biochem. J. 203:169-177.

15. Lipsky, J. J., and Lietman, P. S. 1982. Aminoglycoside inhibition of a renal phosphatidylinositol phospholipase C. J. Pharmacol. Exp. Ther. 220:287-292.

16. Sagawa, N., Bleasdale, J. E., and Di Renzo, G. C. 1983. The effects of polyamines and aminoglycosides on phosphatidylinositol-specific phospholipase $\mathrm{C}$ from human amnion. Biochim. Biophys. Acta 752:153-161.

17. Hendrickson, H. S., and Reinertsen, J. L. 1969. Comparison of metal-binding properties of trans-1,2-cyclohexanediol diphosphate and deacylated phosphoinositides. Biochem. 8:4855-4858.

18. Berridge, M. J. 1983. Rapid accumulation of inositol trisphosphate reveals that agonists hydrolyze polyphosphoinositides instead of phosphatidylinositol. Biochem. J. 212:849858 . 